2016-06

\title{
Redefining the patient-carer model at end of life.
}

\section{Parker, R}

http://hdl.handle.net/10026.1/13066

10.12968/ijpn.2016.22.6.272

Int J Palliat Nurs

All content in PEARL is protected by copyright law. Author manuscripts are made available in accordance with publisher policies. Please cite only the published version using the details provided on the item record or document. In the absence of an open licence (e.g. Creative Commons), permissions for further reuse of content should be sought from the publisher or author. 
Parker R, deVries K \& Coombs MA 2016 'Redefining the patient-carer model at end of life' International Journal of Palliative Nursing 22, (6) 272-277.

Author copy. Accepted 4 February 2016. DOI 10.12968/ijpn.2016.22.6.272

\section{Redefining the carer-patient dyad at end of life}

Roses PARKER PG Dip Nursing, BSc (Hons), RN

Research Assistant

Graduate School of Nursing Midwifery and Health, Victoria University of Wellington

Wellington, New Zealand

Kay deVRIES PhD, MSc, PGCEA, BSc (Hons), RN

Deputy Head of School

School of Health Sciences

University of Brighton

Brighton, United Kingdom

Maureen A COOMBS PhD, MSc, RN

Professor of Clinical Nursing (Critical Care)

Graduate School of Nursing Midwifery and Health, Victoria University of Wellington

Capital and Coast District Health Board, Wellington, New Zealand

Corresponding author:

Maureen A COOMBS

Professor of Clinical Nursing (Critical Care)

Graduate School of Nursing Midwifery and Health, Victoria University of Wellington

Capital and Coast District Health Board, Wellington, New Zealand

Phone number: $+64(0) 44635180$

Maureen.Coombs@vuw.ac.nz 
Number of tables: 1

Number of figures: 0

Number of references: 30

Word count: 3,956

\section{Abstract}

Context. Whilst the patient-carer dyad has been broadly described, there is little exploration about carer-patient models in use.

Aims. To explore types of carer-patient models in use for those with advanced and progressive disease.

Methods. Qualitative interviews were undertaken with patients at risk of dying in the next year and their carers across three sites (residential care home, medical assessment unit, general medical unit). Thematic analysis was undertaken.

Results. Four models of patient-carer dyad were identified. In these, the provision of care and of coordination of care services were important areas and organised differently across the patient, the carer, and alternative sources of support..

Conclusion. A 'one size fits all' carer-patient model is outdated and a new understanding of different types of carer-patient models are required to fully inform care delivered at end of life.

Key words: end-of-life, carer, carer-patient dyad, palliative care, advanced disease 


\section{Introduction}

Due to increased life expectancy, people with advanced and progressive disease are living longer and with increasing numbers of comorbidities. This leads to end-of-life (EOL) care being recognised as occurring over months or even years (Hanratty et al., 2012). Policy and practice seek progressively effective ways of meeting the needs of this population (Robinson et al., 2014), with emphasis on supporting people to living independently in the community (CohenMansfield and Frank, 2008; Davey, J, 2006; Wiles et al., 2011). Carers are acknowledged as essential enablers (Mason et al., 2013; Stoltz et al., 2004) however, the transitions occurring across healthcare settings at end of life are complex (Lawson et al., 2006). Additionally, recognised deficiencies in care planning and care coordination (Mason et al., 2013), have intensified pressure on both patient and carer. Literature reports a lack of recognition for the carer role (Daveson et al., 2014), that the carer voice is ignored (Hanratty et al., 2012), and that healthcare professionals (HCP) assume carer needs to be synonymous with the patient (Bee et al., 2009; Heaton et al., 1999).

Whilst traditional definitions of carers identify relatives as undertaking informal caregiving responsibilities (Mason et al., 2013), patients are finding new models of carer provision (Mason et al., 2013). Perhaps influenced by a societal shift away from the traditional nuclear family (Jack and O’Brien, 2010), a standardised carer-patient model no longer exists and the wider social networks used by patients requires acknowledgment (Procter et al., 2001). Although literature has explored carer-patient relationships in dementia care (Heaton et al., 1999; Oetzel et al., 2015), little is known about the types of carer-patient models in use, specifically for people with progressive disease in their last year of life. For the purpose of this paper, 'carers' are defined as nonprofessionals or lay carers. 


\section{Methods}

Aims

This paper presents one aspect of a larger longitudinal ethnographic study, occurring over 9 months (2015) exploring practices and processes by which transitions in care in the last 12 months of life were managed across three study sites. During data analysis we identified a number of clearly defined models of care delivery with patients and carers each holding different roles and functions.

\section{Sample and setting}

Site 1: Residential care home

A 150-bed unit providing 24-hour registered nursing care to respite patients and permanent residents.

Sites 2 and 3 were located in a tertiary hospital offering a range of specialist and regional tertiary medical and surgical services for a population of 1 million people.

\section{Site 2: Medical assessment unit}

A 24-bed assessment unit for patients expected to remain in hospital for less than 36 hours. In 2014 there were 5,707 admissions with an average length of stay of 2.9 days per admission. 


\section{Site 3: General medical unit}

A 36-bed general medical ward providing services for a range of medical specialities. In 2014 there were 1,501 admissions with an average length of stay of

5.1 days per admission.

\section{Procedures}

Four weeks of field observation were conducted in each site. At this time, people with advanced and progressive illness, who were at high risk of dying in the next year, were recruited using purposeful sampling and tracked for 3-4 months. Participants were identified by senior medical and nursing staff using the validated Supportive and Palliative Care Indicators Tool (Highet et al., 2013). Written consent was obtained at the time of recruitment and a process consent model was adopted (Dewing, 2007). After 3-4 months, the researcher contacted each patient and asked whether they would like to participate in a second interview in which case consent was obtained again.

Interviews were conducted at a mutually agreed time and place. The first interview focussed on diagnosis, prognosis and care journey to date. The second interview focused on experiences of care and transitions. Carers were present and interviewed at the patients' request and the same consent process was used. The nature and function of the carer role was explored across interviews. 


\section{Data analysis}

Field data and interview recordings were transcribed, verified against original recordings, anonymised, read and re-read, coded and thematically analysed (Braun and Clarke, 2006; Thomas, 2006). NVivo was used to support data management. Once coding was complete, two authors (MC and RP) discussed the findings. Data addressing relationships between patients and their carers underwent separate analysis. Different carer-patient models were identified as carer-patient dyads described changes in care circumstances over time. All authors discussed and agreed the final models.

\section{Ethics and governance}

This study received approval from the Regional Advisory Group - Maori (Ref. no. RAG-M 2014/346), the Health and Disability Ethics Committee (Southern Health Region) (14/STH/180) and Victoria University of Wellington Human ethics committee (RM 21627). Local approval was given to access and collect data at each site. Site specific research governance procedures were upheld.

\section{Results}

Of the 29 patients recruited into the main study, 17 patients noted different models of carer-patient activity. All 17 patients had a first baseline interview at enrolment, seven participants had a second interview giving a total of 24 interviews. Of these, eight were conducted with the carer and patient, and three solely with the carer. Carers were identified as: spouses $(n=5)$; siblings $(n=1)$; adult children $(n=9)$; and alternative carers $(n=2)$. Patients aged 60-98 (mean 84.1) and had a range of medical diagnoses. See table 1 for demographic information. 
[Insert table 1]

Findings identified that, contrary to the literature, there was not one, but four carer-patient models for patients with advanced and progressive disease in the last year of life. In these, the responsibility for different functions, namely for coordination of care services and for provision of care, was held by different individuals. The four models identified were: dependence on carer for care and co-ordination (community based); dependence on carer for care and independent for co-ordination (community based); independent for coordination with dependence on alternative help for care (community based); dependent on carer for coordination whilst in an organisational care settings for care. The patient-carer model in use was dynamic and changed over time to meet patient need as the patient's illness trajectory shifted.

\section{Dependence on carer for provision of care and coordination of care}

This model described circumstances where patients were dependent on their carers for both provision of direct care and coordination of care services in the last year of life. Caring duties included providing food, meeting hygiene needs, and managing medications. Coordination duties included liaising with HCP, managing patient finances, and making decisions about the health care services. Carers in this model took full responsibility in providing care and coordination:

"It becomes virtually 24 hours care and then gradually down, down...but you're a nurse, you're a physiotherapist, you're a runner around in the car, you're appointments...you're absolutely everything." 
[Wife: Res M]

The patient position here was one of compliance with and trust in their carer and HCP. These patients were often so reliant on their carer that they were unaware of what their treatment plan was:

"I can't remember most of it, my daughter knows more about it than I do...my daughter will give you all the technical side. My technical knowledge is nil."

[Patient: Gen H]

Dependence on carer for provision of care and independent for coordination of care

In this model, whilst the patient was dependent on their carer for caring responsibilities, the patient was independent in their ability coordinate their care services. Some carers used hospital admissions opportunity for respite, because the carer could rely on hospital staff to do the caring and did not need to be present for the coordination as the patient was independent in that regard. These patients based the decision to come into hospital on their perception of their carer's ability to cope. Below is an example of a patient-carer model where a husband had been providing direct care ("things he's been asked to do lately") but was clearly not coordinating care as the patient made the decision regarding hospitalisation:

"Interviewer: ... the ambulance had decided to bring you here to give your husband a break?

Patient: Well they made me make the decision.

Interviewer: How did you feel about making the decision yourself...? 
Patient: Well it was important, my husband's comment, he said to me 'give me a break'. Yes. You know he's 96. It's not fair, with things he's been asked to do lately."

[Patient: M12]

HCPs did not always realise the patient had taken responsibility for care coordination and assumed that if patients were unable to undertake direct care, they were also unable to undertake care coordination. Consequently, patients' in this model wanted to be informed about their care services and were often dissatisfied with HCP communication:

"So I thought oh why didn't you tell me this. To you it's all just clinical, just want a body on a slab...they don't tell you something unless you ask. So you have to already know that these things are available... You have to ask the right questions...It's communication things it all comes out in the communication...the other problem is I actually am one of those people that even though I'm crook I like to know what's going on."

[Patient: Gen K]

It was unclear whether patients had chosen to take responsibility for coordination of care services, or whether this had been taken out of necessity, secondary to the limited capacity of their carer. 


\section{Independent for coordination of care with dependence on alternative help for provision of care}

Here, patients coordinated their own care during the last year of life and, due to the absence of an appropriate family member or friend, made alternative arrangements to support their care needs. This included advertising spare rooms in their home for rent to 'flatmates' whose presence enabled them to remain in their own homes as opposed to transitioning to a residential care home. The caring responsibility was shared between flatmates and professional health services based in the community. Depending on the health status of the patient, care needs could vary from simply having someone present in case of emergencies to daily assistance with personal hygiene. It was challenging for patients to communicate the nature of their carer relationship and this became problematic when establishing patient eligibility for funded support. In the quote below, flatmates provided the patient with a safety-net for emergencies and assistance in daily tasks. However, their presence meant that the patients' entitlement to funded support was questioned:

"And they [flatmates] came to stay with me on the undertaking that we all look after ourselves and they weren't any way playing nursemaid to me... that's why they came there and I don't want to lose them. And yet [care agency] more or less takes the attitude, if I've got flatmates there they should be able to help me."

[Patient: Gen L]

Although the coordination responsibility for patients was burdensome at times, and even though some patients struggled with taking responsibility for this activity, patients were determined to maintain this independence: 
"I've developed about making phone calls and fronting up to counters and so on... just the merest suggestion that anything's official, so just making an appointment is more than I can cope with, but that's just a psychological problem that I have and I have to manage...And no one else is going to do it."

[Patient: Gen L]

Dependent on carer for coordination of care whilst in an organisational care settings for care provision

The final model identified where carers were actively involved in the coordination of health care, even though patients were cared for in organisational health care settings e.g. residential care home. In this environment, carers were observed organising outpatient appointments, updating on medication changes, etc. For some carers, whilst their coordination role continued, they found it challenging to relinquish previous caregiving responsibilities:

"I found it difficult to come up here because I felt that the staff weren't just quite aux fait with [medical condition]...tending to some of the things that I did that I felt that they should have done because they're professionals..., it took me nearly that first year to actually get at what was needed to be done, what cares [Patient] needed."

[Wife: Res M]

Carers felt that their involvement with the patient was essential and were concerned for what would happen to the patient if they did not undertake this function: 
"[The] elderly need someone to speak up for them even at the rest home, patients are neglected because they don't have someone to speak up for them."

[Field notes from an informal conversation with a patients' daughter]

\section{Discussion}

Of those models identified, the one most explored in literature is where carers took full responsibility for care and coordination to maintain the patient in the community. This is clearly a complex and demanding role for carers with carer burden and potential for carer fatigue well documented (Daveson et al., 2014; Jack and O'Brien, 2010; Mason et al., 2013). We suggest given this risk for carers, HCP need to monitor and work to prevent carer burnout, cognisant of the many recommendations made for supportive carer interventions (Heaton et al., 1999; Jack and O'Brien, 2010; Laugaland et al., 2012; Oetzel et al., 2015; Procter et al., 2001; Thomas, 2004).

The second model outlined for patients in the last year of life described where patients care needs were met by carers yet patients continued to hold responsibility for, coordination of care services. Interestingly, whilst it has been suggested that carers of this population risk exclusion from discharge planning (Bee et al., 2009; Heaton et al., 1999; Procter et al., 2001; Rowe, 2012), in this study it was patients who needed more communication from HCP than was being offered. This may be resultant from HCP assumptions that carers were responsible for care coordination (Hanratty et al., 2012; Murphy et al., 2015). We suggest that HCP recognise that this model is distinct from the traditional model of carer-patient relationship and ensure patients are kept informed, even with their dependence on carers for care provision. 
Patients who utilise alternative models for care and coordination during the last year of their life, reflect increasingly complex care circumstances (Mason et al., 2013; Procter et al., 2001) and the changing nature of caregiving in society (Fine and Glendinning, 2005). Whilst innovative and resourceful, these patients do not 'fit' current health care services and may be disadvantaged with regards to available community services. These novel and emerging care arrangements need wider and formal recognition.

Little consideration has been given to the nature of the carer-patient dyad once the patient is in a formal care setting. Carers of patients in such settings perform a vital role in care coordination, patient advocacy (Bridges et al., 2010; Li et al., 2004) and in maintaining continuity on admission to residential care (Davies and Nolan, 2006) and as end of life approaches (Shield et al., 2010). This also has implications for patients who live in residential care homes but who do not have a carer. It raises questions as to who does provide this coordination role.

The models developed from data in this study illustrate carer-patient dyad structures that expand on traditional carer-patient models. Some of these arrangements are beginning to be recognised, for example, the New Zealand Carers' Strategy Action Plan recognises that patients may have care needs outside the scope of traditional health provision (Ministry of Health, 2014; Ministry of Social Development, 2014) and in the UK, concerted effort has gone into raising HCP awareness of the contribution of carers (Bee et al., 2009; Department of Health, 2010). 
Findings from this study suggest inflexibility remains within the health system for patients using alternative care arrangements in the last year of life. There is evidence that hospital-based HCP may not fully understand the complex and dynamic needs of carers and community service provision for patients at end of life.

\section{Limitations}

The sample size may be insufficient to capture all potential models of carer-patient dyad currently used by patients in the last year of life and a larger study is required to either strengthen or dispute these models. However, the purpose of this paper is to challenge the concept of a singular model of carer-patient dyad and to suggest alternative models which may exist. Further work is require to identify what factors influence the transition from one model to another, and offer guidance to HCP on the tailored assessment of care needs and coordination of services in use in each patient carer model.

Data collection took place in just one tertiary hospital and one residential care home in New Zealand and may not be transferable to other settings. To assist in making transferability judgements, we have provided detail on the population, data collection and data analysis.

\section{Conclusion}

Four carer-patient models for managing provision of care and coordination of care services were identified in use for patients likely to be in the last year of life. In each model, the responsibility varied between carer, patient and other support sources, and flexed to meet the changing needs of the patient. This refutes the 'one size fits all' definition of the carer-patient dyad model. Historical models in this area are outdated and a new understanding of the carer- 
patient dyad is required. By taking a tailored, flexible approach that is cognisant of the trajectory of the patient's illness , HCP may be able to work with carer-patient dyads to instigate care provision systems preferable to patients and carers, as well as being more efficient use of resources (Stoltz et al.,

2004).

\section{References}

Bee, P.E., Barnes, P., Luker, K.A., 2009. A systematic review of informal caregivers' needs in providing home-based end-of-life care to people with cancer. J. Clin. Nurs. 18, 1379-1393. doi:10.1111/j.1365-2702.2008.02405.x

Braun, V., Clarke, V., 2006. Using thematic analysis in psychology. Qual. Res. Psychol. 3, 77-101. doi:http://dx.doi.org/10.1191/1478088706qp063oa

Bridges, J., Flatley, M., Meyer, J., 2010. Older people's and relatives' experiences in acute care settings: systematic review and synthesis of qualitative studies. Int. J. Nurs. Stud. 47, 89-107. doi:10.1016/j.ijnurstu.2009.09.009

Cohen-Mansfield, J., Frank, J., 2008. Relationship between perceived needs and assessed needs for services in community-dwelling older persons. The Gerontologist 48, 505-516.

Daveson, B.A., Harding, R., Shipman, C., Mason, B.L., Epiphaniou, E., Higginson, I.J., Ellis-Smith, C., Henson, L., Munday, D., Nanton, V., Dale, J.R., Boyd, K., Worth, A., Barclay, S., Donaldson, A., Murray, S., 2014. The Real-World Problem of Care Coordination: A Longitudinal Qualitative Study with Patients Living with Advanced Progressive Illness and Their Unpaid Caregivers. PLoS ONE 9, e95523. doi:10.1371/journal.pone.0095523

Davey, J, 2006. Aging in Place: The Views of Older Homeowners on Maintenance, Renovation and Adapetation - Ministry of Social Development.

Davies, S., Nolan, M., 2006. "Making it better": self-perceived roles of family caregivers of older people living in care homes: a qualitative study. Int. J. Nurs. Stud. 43, 281-291. doi:10.1016/j.ijnurstu.2005.04.009

Department of Health, 2010. Recognised, Valued and Supported: next steps for the carers strategy - Publications - GOV.UK [WWW Document]. URL https://www.gov.uk/government/publications/recognised-valued-and-supported-next-steps-for-the-carers-strategy (accessed 12.27.15).

Dewing, J., 2007. Participatory research A method for process consent with persons who have dementia. Dementia 6, 11-25. doi:10.1177/1471301207075625

Fine, M., Glendinning, C., 2005. Dependence, independence or inter-dependence? Revisiting the concepts of and. Ageing Soc. 25, 601-621. doi:10.1017/S0144686X05003600

Hanratty, B., Holmes, L., Lowson, E., Grande, G., Addington-Hall, J., Payne, S., Seymour, J., 2012. Older Adults' Experiences of Transitions Between Care Settings at the End of Life in England: A Qualitative Interview Study. J. Pain Symptom Manage. 44, 74-83. doi:10.1016/j.jpainsymman.2011.08.006

Heaton, J., Arksey, H., Sloper, P., 1999. Carers' experiences of hospital discharge and continuing care in the community. Health Soc. Care Community 7, 9199. 
Highet, G., Crawford, D., Murray, S.A., Boyd, K., 2013. Development and evaluation of the Supportive and Palliative Care Indicators Tool (SPICT): a mixedmethods study. BMJ Support. Palliat. Care bmjspcare-2013-000488. doi:10.1136/bmjspcare-2013-000488

Jack, B., O'Brien, M., 2010. Dying at home: community nurses' views on the impact of informal carers on cancer patients' place of death. Eur. J. Cancer Care (Engl.) 19, 636-642. doi:10.1111/j.1365-2354.2009.01103.x

Laugaland, K., Aase, K., Barach, P., 2012. Interventions to improve patient safety in transitional care - a review of the evidence. Work 41, $2915-2924$.

Lawson, B., Burge, F.I., Critchley, P., McIntyre, P., 2006. Factors associated with multiple transitions in care during the end of life following enrollment in a comprehensive palliative care program. BMC Palliat. Care 5, 4. doi:10.1186/1472-684X-5-4

Li, H., Melnyk, B.M., McCann, R., 2004. Review of intervention studies of families with hospitalized elderly relatives. J. Nurs. Scholarsh. Off. Publ. Sigma Theta Tau Int. Honor Soc. Nurs. Sigma Theta Tau 36, 54-59.

Mason, B., Donaldson, A., Epiphaniou, E., Nanton, V., Shipman, C., Daveson, B., Harding, R., Higginson, I., Munday, D., Barclay, S., others, 2013. Coordination of care for people at risk of dying in the next 12 months: a multi-site prospective study and consensus seeking exercise. Lond. Natl. Inst. Health Res. Serv. Deliv. Organ. Programme 1-194.

Ministry of Health, 2014. Individualised Funding [WWW Document]. Minist. Health NZ. URL http://www.health.govt.nz/your-health/services-andsupport/disability-services/types-disability-support/individualised-funding (accessed 10.21.15).

Ministry of Social Development, 2014. The New Zealand Carers' Strategy Action Plan for 2014 to 2018.

Murphy, D., Crowley, R., Spencer, A., Birch, M., 2015. When can I go home? A prospective case control study to improve communication with patients regarding their diagnosis, treatment plan and likely discharge date. N. Z. Med. J. 128, 53-58.

Oetzel, J., Simpson, M., Berryman, K., Iti, T., Reddy, R., 2015. Managing communication tensions and challenges during the end-of-life journey: perspectives of Māori kaumātua and their whānau. Health Commun. 30, 350-360. doi:10.1080/10410236.2013.861306

Procter, S., Wilcockson, J., Pearson, P., Allgar, V., 2001. Going home from hospital: the carer/patient dyad. J. Adv. Nurs. 35, 206-217. doi:10.1046/j.13652648.2001.01838.x

Robinson, J., Gott, M., Ingleton, C., 2014. Patient and family experiences of palliative care in hospital: what do we know? An integrative review. Palliat. Med. 28, 18-33. doi:10.1177/0269216313487568

Rowe, J., 2012. Great expectations: a systematic review of the literature on the role of family carers in severe mental illness, and their relationships and engagement with professionals. J. Psychiatr. Ment. Health Nurs. 19, 70-82. doi:10.1111/j.1365-2850.2011.01756.x

Shield, R.R., Wetle, T., Teno, J., Miller, S.C., Welch, L.C., 2010. Vigilant at the End of Life: Family Advocacy in the Nursing Home. J. Palliat. Med. 13, 573-579. doi:10.1089/jpm.2009.0398

Stoltz, P., Udén, G., Willman, A., 2004. Support for family carers who care for an elderly person at home - a systematic literature review. Scand. J. Caring Sci. 18, 111-119. doi:10.1111/j.1471-6712.2004.00269.x

Thomas, D.R., 2006. A General Inductive Approach for Analyzing Qualitative Evaluation Data. Am. J. Eval. 27, 237-246. doi:10.1177/1098214005283748

Thomas, P. PierreLalloue, FabriceHazif-Thomas, CyrilBillon, RémyViéban, FrançoisClément, Jean-Pierre, 2004. Reasons of informal caregivers for institutionalising dementia patients previously living at home: the Pixel study. Int. J. Geriatr. Psychiatry 19, 127-135. doi:10.1002/gps.1039 
Wiles, J.L., Leibing, A., Guberman, N., Reeve, J., Allen, R.E.S., 2011. The Meaning of “Ageing in Place” to Older People. The Gerontologist gnr098. doi:10.1093/geront/gnr098 
Table 1

\begin{tabular}{|c|c|c|c|c|c|c|}
\hline $\begin{array}{l}\text { Patient } \\
\text { ID } \\
\end{array}$ & Gender & Age & Diagnosis & $\begin{array}{l}\text { Status at } 3 / 4 \\
\text { months }\end{array}$ & Carer & Type of model* \\
\hline \multicolumn{7}{|c|}{ Residential care home $n=5$} \\
\hline Res B & M & 92 & MS & Alive & Care home, previously wife & 1 \\
\hline $\operatorname{Res} \mathrm{C}$ & $\mathrm{F}$ & 80 & MS & Alive & Husband & 1 \\
\hline Res D & $\mathrm{F}$ & 90 & Frailty & Withdrew & Daughter & 1 \\
\hline Res K & $\mathrm{F}$ & 98 & Cardiac, oncology & Alive & Son & 4 \\
\hline Res M & $\mathrm{M}$ & 80 & Parkinson's & Alive & Care home, previously wife & 1,4 \\
\hline \multicolumn{7}{|c|}{ Medical assessment unit $n=6$} \\
\hline M4 & M & 91 & Heart failure & Deceased & Daughter & 1,4 \\
\hline M6 & M & 61 & Parkinson's, COPD & Deceased & Alternative & 3 \\
\hline M9 & $\mathrm{F}$ & 86 & Heart disease & Deceased & Daughter & 1 \\
\hline M12 & $\mathrm{F}$ & 86 & Respiratory & Deceased & Husband & 2 \\
\hline M13 & $\mathrm{F}$ & 83 & COPD & Alive & Daughter & 2 \\
\hline M14 & $\mathrm{F}$ & 97 & Heart failure, liver disease & Deceased & Daughter & 4 \\
\hline \multicolumn{7}{|c|}{ General medical unit $n=5$} \\
\hline Gen B & M & 91 & Oncology & Unable to contact & Son & $1,3,4$ \\
\hline Gen H & $M$ & 77 & Oncology & Deceased & Daughter & 1 \\
\hline Gen I & $\mathrm{F}$ & 83 & COPD & Unable to contact & Daughter & 1 \\
\hline Gen K & $\mathrm{F}$ & 60 & Oncology & Deceased & Sister & 2,3 \\
\hline Gen L & $\mathrm{F}$ & 81 & Heart failure & Alive & Alternative & 3 \\
\hline
\end{tabular}

* Key for models of care provision

$1=$ Dependence on carer for provision of care and coordination of care

$2=$ Dependence on carer for provision of care and independent for coordination of care

$3=$ Independent for coordination of care with dependence on alternative help for provision of care

$4=$ Dependent on carer for coordination of care whilst in an organisational care setting for care provision 